\section{The mechanism of the effects of Monascus jmbA rice on increased platelet count in Wistar rats infected with Dengue virus serotype 3}

\author{
Erwin Astha Triyono \\ Department of Internal Medicine, \\ Faculty of Medicine, Airlangga \\ University, Surabaya, Indonesia
}

\begin{abstract}
Background: Several traditional medicines have been developed among communities as part of the efforts to improve thrombocytopenia in patients with Dengue virus infection (DVI). Among those efforts is the administration of Monascus jmbA rice (MJR), which is rice fermented with Monascus purpureus. The administration of MJR is believed to increase the platelet count in patients with DVI.

Aim: The objective of this study is to elucidate the mechanism of the effects of MJR on increased levels of platelets in DVI serotype 3 through changes in IL-3, IL-6,
\end{abstract} IL-11 and TNF- $\alpha$.

Methods: It was a true experimental laboratory study using the randomized posttest only control group design. The study compared between groups of wistar rats were being treated only with group IVD wistar rats who experienced treatment followed by administration of MJR as well as groups of wistar rats without any treatment as a control group.

Results: The increase in platelet count in the group treated with DVI + MJR was higher than that treated with only DVI and the difference was a significant $(\mathrm{P}<0.05)$. Increased levels of TNF- $\alpha$ in the group treated with DVI + MJR were lower than that treated with only DVI and the difference was significant $(\mathrm{P}<0.05)$. The significant levels of the causal relationship of TNF- $\alpha$ with IL-6, TNF- $\alpha$ with IL-11 and IL6 with platelets were $0.044(\mathrm{P}<0.05), 0.029$ $(\mathrm{P}<0.05)$ and $0.041(\mathrm{P}<0.05)$, respectively.

Conclusion: MJR is capable of increasing platelet count through the role of TNF$\alpha$ and IL- 6 in Wistar rats infected with DVI serotype 3 .

\section{Introduction}

Dengue virus infection (DVI) causes serious morbidity and mortality in many tropical and sub-tropical countries where
DVI undergoes two main pathophysiological changes: an increase in vascular permeability capable of causing hemoconcentration, and a hemostatic disorder that include vasculopathy, coagulopathy, and thrombocytopenia. ${ }^{1,2}$ Thrombocytopenia is mainly associated with hemorrhagic manifestations and severity of DVI. Thrombocytopenia in DVI may constitute an effect of decreasing megakaryopoiesis. The decrease may be caused by DVI direct infection of hematopoietic progenitor cells, the release of cytokines inhibiting hematopoiesis, the effects of platelet destruction due to the inflammatory process and the result of platelet aggregation in blood vessels. ${ }^{3}$ Currently, there is no specific treatment for DVI so that the management remains more supportive and symptomatic in nature.

Several traditional medicines have been developed among communities as part of the efforts to improve thrombocytopenia in patients with DVI. Among those efforts is the administration of Monascus jmbA rice (MJR), which is rice fermented with Monascus purpureus. The administration of MJR is believed to increase the platelet count in patients with DVI. Research in the Laboratory of Microorganism Biosystematic and Genetics, Research Center for Biology of Indonesian Scientific Knowledge Agency (LIPI), Bogor, showed that mice treated MJR indicated a significant increase in platelet count. Additionally, in the course of the study, those mice remained active and no significant change in conditions was observed. ${ }^{4}$ Another study showed that patients with DHF who received the extract of guava leaves and Monascus purpureus demonstrated a significant increase in platelet count compared with the control group. ${ }^{5}$ To date, however, the quick normal platelet count in patients with DVI who receive MJR therapy remains unclear.

Increased platelet count with the administration of MJR is thought to be through the pathway of increased thrombopoiesis, backed by the anti-inflammatory effects of its metabolites, monacolin $\mathrm{K}$, ankaflavin and monascin. Monacolin Kwith its similar structure as lovastatin has statin-like effects thought to be capable of affecting the activity of macrophages. ${ }^{6}$ Increased thrombopoiesis process requires the stem-cell factor produced by activated monocytes or macrophages. Statins are capable of affecting gene expression and function of cells of the natural or acquired immune systems, such as macrophages, dendritic cells, and $\mathrm{T}$ cells. Most of these effects are related to the blockade of statins in GTPase isoprenylation. Additionally, statins have an inhibitory effect on platelet aggregation induced by
Correspondence: Erwin Astha Triyono, Department of Internal Medicine, Faculty of Medicine, Airlangga University, Jl. Prof. Dr. Moestopo no. 6-8,60131, Surabaya, Indonesia.

Tel. +62 8123259941

E-mail: erwintriyono@yahoo.com

Key words: Monascus jmbA rice, platelets, dengue virus serotype 3 , wistar rats.

Conflict of interest: The author declares no potential conflicts of interest.

Funding: None.

Clinical trials: The experimental unit used in the study was the white rats (Rattus norvegicus) of the Wistar strain obtained from the Biochemistry Laboratory of Laboratory Animal Unit of Airlangga University, Faculty of Medicine.

Acknowledgements: The author would like to thank the following companies for their assistance with the collection of my data so that my articles have been presented an Infectious Diseases, Biothreats, and Military Medicine (INSBIOMM).

Conference presentation: This paper was presented at the International conference on Infectious Diseases, Biothreats, and Military Medicine (INSBIOMM).

Dedication: The article is dedicated to the doctoral education program.

Received for publication: 17 February 2020. Accepted for publication: 1 July 2020.

This work is licensed under a Creative Commons Attribution-NonCommercial 4.0 International License (CC BY-NC 4.0).

(Copyright: the Author(s), 2020

Licensee PAGEPress, Italy

Infectious Disease Reports 2020; 12(s1):8720 doi:10.4081/idr.2020.8720

adenosine diphosphate (ADP) and on thromboxane B2 synthesis. ${ }^{7}$

DVI development in animal models is essential to understanding viral pathogenesis and identifying therapeutic targets. DVI tested on a group of non-human primates indicated the capability of sustaining replication of the virus and developing strong immune responses, preventing clinical manifestations. DVI clinical manifestations and severity of the disease vary greatly depending on various factors, including host characteristics, the virulence of the virus, cell tropism, and immune responses..$^{8-10}$

Virus strains contribute to the increased risk of incidence of DHF. DEN-2 is the 
most potent, followed by DEN-3, DEN-4 and DEN-1. Serotypes DEN-2 and DEN-3 are generally associated with clinical manifestations of severe DHF, while DEN-4 is rare and generally associated with mild DHF. ${ }^{11-13}$

The present study was conducted on Wistar rats on the grounds that they constituted an appropriate model to study the effects of DVI and the administration of MJR. In addition, Wistar rats have been considered the standard model of experimental animals to examine the activity of several mediators and peripheral blood cells, especially platelet counts with regard to both DVI and the administration of MJR. ${ }^{4,10}$

In addition to demonstrating the mechanism of increased thrombopoiesis through providing MJR, the purpose of the present study was to elucidate the mechanism of the effects of MJR on increased platelets in Wistar rats infected with dengue virus serotype 3 through changes in stem-cell factors (IL-3, IL-6, IL -11 and TNF- $\alpha$ ) produced by activated monocytes or macrophages.

\section{Materials and Methods}

The present study was a true experimental laboratory study conducted using the randomized post-test only control group design. It compared groups of Wistar rats treated with only DVI, Wistar rats treated with DVI followed by the administration of MJR as well as untreated Wistar rats serving as the control group.

The experimental unit used in the study was the white rats (Rattus norvegicus) of
Wistar strain obtained from the Biochemistry Laboratory of Laboratory Animal Unit of Airlangga University Faculty of Medicine. Three-month-old male Wistar rats weighing 200-300 grams with the healthy condition were selected randomly. Characteristics of healthy rats are shiny fur, shining eyes, and agile movements. Wistar rats whose health conditions did not like those characteristics were excluded from the study.

The dropout criterion for Wistar rats in the study was confirmed by consulting the veterinarian who agreed that the animals had no physical injury or illness that could lead to death not linked to the study in the period after the initiation of the study.

The selected Wistar rats were subsequently placed in cages in appropriate environmental conditions in order for helping Wistar rat adaptation and clinically evaluated for $7 \times 24$ hours.

A minimum of nine (rounded) Wistar rats for each group was required so that the minimum total sample size was 27 rats. In anticipation of dead mice during the study, the number of rats for treatment groups 2 and 3 was increased to 12 rats, while the number of rats for group 1 or control group was reduced to 5 rats as recommended by the research ethics committee; thus, the total sample used in the study amounted to 29 rats.

The study consisted of several stages. Wistar rats meeting the inclusion criteria were placed in animal cages and allowed to adapt to the environment for 1 week and were clinically evaluated. The study subjects meeting the exclusion criteria were excluded from the sample. The successfully adapted study subjects were subsequently assigned randomly to treatment groups. The treatment groups in the study were divided into three group, control group with no DVI treatment or administration of MJR, group treated with DVI 3 serotype (DENV 3) alone and observed for 1 week, and group treated with DVI 3 serotype (DENV 3) followed by administration of MJR for 1 week.

The study subjects from Group 1 were sacrificed on day 1 while those from Groups 2 and 3 were killed on day 8 for collection of peripheral blood specimens and evaluation by measuring platelet count and the levels of IL-3, IL-6, IL-11 and TNF- $\alpha$.

\section{Procedures for injection of Dengue virus serotype 3 (DEN 3)}

Wistar rats of the same group were taken from their cage. Dengue virus infections were achieved by injecting Dengue virus serotype 3 (DEN 3) to Wistar rats. Dengue virus serotype 3 (DEN 3) at a dose of $10^{5} \mathrm{pfu} / \mathrm{mL}$ was subcutaneously injected under the central hind limb skin with a total volume of $0.2 \mathrm{ml}$ divided equally for the right and left legs..$^{8.10}$

\section{Procedures for feeding Monascus jmbA rice}

MJR was prepared in the form of powder. It was dissolved in distilled water, stirred and filtered and then fed to each of Wistar rats with a maximum feeding volume of $1 \mathrm{~mL}$ per animal orally daily for 7 days using a nasogastric tube. The recommended dose of MJR was 0.5 g/animal/day. ${ }^{4}$

\section{Procedures for killing and peripher- al blood sampling}

On days 1 and 8, the blood of Wistar

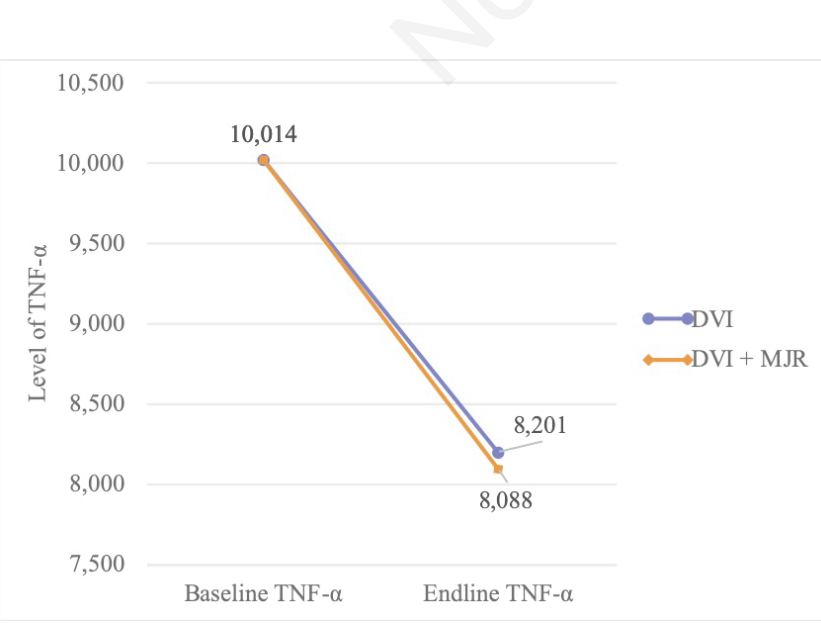

Figure 1. Comparison of mean decrease in serum TNF- $\alpha$ between rats treated with Dengue virus infection (DVI) and Monascus jmbA rice and rats treated treated with DVI only.

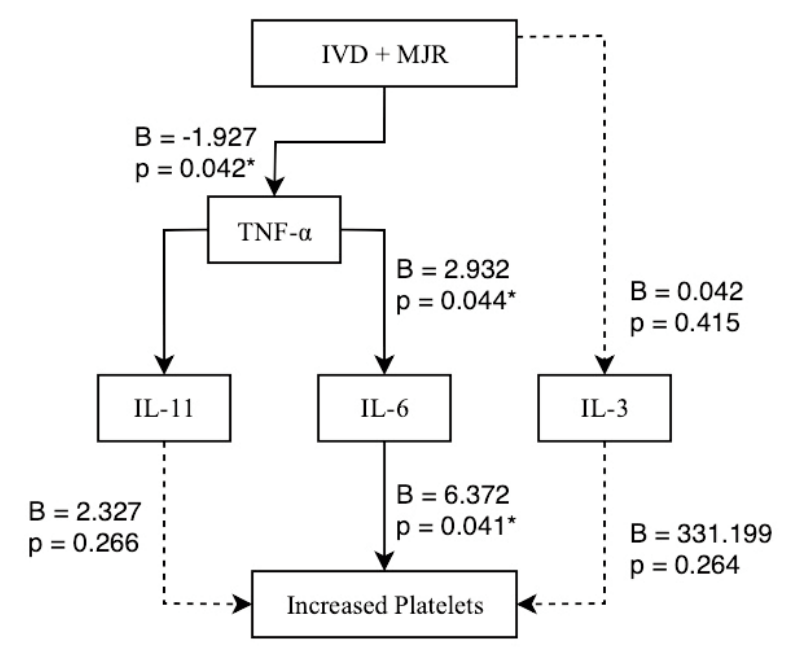

Figure 2. Path Analysis. 
rats was sampled under anesthesia by intramuscular injection of a mixture of ketamine $(100 \mathrm{mg} / \mathrm{kg})$ and xylazine $(10 \mathrm{mg} / \mathrm{kg} \mathrm{BW})$ to the thigh muscles. After perfectly anesthetized, Wistar rats were placed in a supine position on the dissection board. Subsequently, the chest cavity of the animals was dissected for blood drainage of the right heart using a 23G-needle syringe. An approximately $5 \mathrm{~mL}$ of blood was collected and immediately sent to Prodia Clinical Laboratory where the first $1 \mathrm{~mL}$ was put into a vial containing EDTA anticoagulant for platelet examination. The remaining $4 \mathrm{~mL}$ was put into a vial without anticoagulant for centrifugation in order to obtain serum to be stored for further examination by ELISA. ${ }^{14-16}$

\section{Results}

There was no drop out in the course of the study.

The mean increase in platelet count for the group treated with DVI and MJR was higher than the group treated with only DVI and a significant difference was found at $\mathrm{P}<0.05$. (Table 1)

The mean increase in the levels of TNF$\alpha$ for the group treated with DVI and MJR was lower than the group treated with DVI only and a significant difference was found at $\mathrm{P}<0.05$ (Table 2; Figure 1).

The causal relationship between MJR and the levels of TNF- $\alpha$ had a significance level of $0.042 \quad(\mathrm{P}<0.05)$, meaning that affects the levels of TNF- $\alpha$. Similarly, the causal relationship between TNF- $\alpha$ and the levels of IL- $6,(\mathrm{P}=0.044<0.05)$, the causal relationship between TNF- $\alpha$ and the levels of IL-11 $(\mathrm{P}=0.029<0.05)$, the causal relationship between IL-6 and platelet count $(\mathrm{P}=0.041<0.05)$ are significant. A positive constant value (B) indicates the positive effect of the independent variable, this means that the higher the levels of TNF- $\alpha$, the higher the levels of IL-6 and IL-11. Similarly, the higher the levels of IL-6, the higher platelet count resulted to be.

The mechanism path of the effects of MJR on increased platelets in Wistar rats infected with Dengue virus serotype 3 initiated with feeding MJR led to stimulation of TNF- $\alpha$, causing an increase in IL- 6 and subsequently capable of increasing platelet count (Figure 2).

Analysis of the most dominant factor with regard to increasing platelets after administration of MJR in DVI can be seen in Table 4.

Table 4 shows that the most dominant variable with regard to increased platelets after administration of MJR in Dengue virus infection was TNF- $\alpha$ with the largest standardized coefficient (B) of 19.738.

\section{Discussion}

Effects of Monascus jmbA rice on increased platelets in Dengue Virus Infection

The mean increase in platelet count for the group treated with DVI and MJR was higher than for the group treated with only DVI and a significant difference was found at $\mathrm{P}<0.05$ (Table 2); thus, this study demonstrated that administration of MJR had an effect on increasing platelet count in Wistar rats infected with Dengue virus serotype 3. Previous studies also showed that rats were treated with MJR showed a significant increase in platelet count. ${ }^{4,5}$

Effects of Monascus jmbA rice on Effects of Monascus jmbA rice on increased platelets through changes in the levels of IL-3 in Dengue Virus Infection

The mean increase in the levels of IL-3 for the group treated with DVI and MJR was lower than for the group treated with only DVI but significant difference was not found at $\mathrm{P}>0.05$; thus, this study did not demonstrate that administration of MJR had an effect on increased platelet count through changes in the levels of IL-3 in Wistar rats infected with Dengue virus serotype 3.

\section{Effects of Monascus jmbA rice on increased platelets through changes in the levels of IL-6 in Dengue Virus Infection}

The mean increase in the levels of IL-6 for the group treated with DVI and MJR

Table 1. Mean and standard deviation of platelet count in groups 1 and 3 rat blood plasma.

\begin{tabular}{lcccc} 
Groulp & \multicolumn{2}{c}{$\begin{array}{c}\text { Platelet count } \\
\text { Mean }\end{array}$} & $\begin{array}{c}\left(10^{3} / \mathrm{mL}\right) \\
\text { SD }\end{array}$ & P \\
1 (control) & 847.000 & 74.000 & 5.494 & $0.017^{*}$ \\
3 (DVI + MJR) & 1054.917 & 189.409 & & \\
\hline
\end{tabular}

$\mathrm{SD}=$ Standard Deviation; $* \mathrm{P}<0.05$ significantly different (ANOVA).

Table 2. Mean and standard deviation of levels of TNF- $\alpha$ in groups 1 and 3 rat blood plasma.

\begin{tabular}{lcccc} 
Group & $\begin{array}{c}\text { Level of TIN }-\alpha(\mathrm{pg} / \mathrm{mL}) \\
\text { Mean }\end{array}$ & SD & P \\
1 (control) & 10.014 & 1.449 & 4.963 & $0.042^{*}$ \\
3 (DVI + MJR) & 8.088 & 1.684 & & \\
\hline
\end{tabular}

$\mathrm{SD}=$ Standard Deviation; $* \mathrm{P}<0.05$ significantly different (ANOVA).

Table 3. Regression analysis (causal relationships) among study variables.

\begin{tabular}{llccc} 
No. & Variables & $\begin{array}{c}\text { Dependent } \\
\text { variables }\end{array}$ & $\begin{array}{c}\text { Unstandardived } \\
\text { coefficients (B) }\end{array}$ & P-value \\
1 & MJR & TNF- $\alpha$ & -1.927 & $0.042 *$ \\
2 & MJR & IL-3 & 0.042 & 0.415 \\
\hline 3 & TNF- $\alpha$ & IL-6 & 2.932 & $0.044^{*}$ \\
4 & TNF- $\alpha$ & IL-11 & 3.175 & $0.029^{*}$ \\
\hline 5 & IL-3 & platelets & 331.199 & 0.264 \\
6 & IL-6 & platelets & 6.732 & $0.041^{*}$ \\
\hline 7 & IL-11 & platelets & 2.327 & 0.266 \\
\hline
\end{tabular}

*Significantly different at $\mathrm{P}<0.05$.

Table 4. Regression analysis (causal relationship) among the study variables with regard to increased platelet.

Dependent variable Independent variables Unstandardized coefficients (B)

\begin{tabular}{|c|c|c|}
\hline Platelets & TNF- $\alpha$ & $2.932 \times 6.732=19.738$ \\
\hline & IL-6 & 6.732 \\
\hline
\end{tabular}


was lower than for the group treated with only DVI but a significant difference was not found at $\mathrm{P}>0.05$; this study did not demonstrated that administration of MJR had an effect on increased platelet count through changes in the levels of IL-6 in Wistar rats infected with Dengue virus serotype 3 .

\section{Effects of Monascus jmbA rice on increased platelets through changes in the levels of IL-11 in Dengue Virus Infection}

The mean decrease in the levels of IL11 for the group treated with DVI and MJR was higher than for the group treated with only DVIs but a significant difference was not found at $\mathrm{P}>0.05$; thus, this study did not demonstrated that administration of MJR had an effect on increased platelet count through changes in the levels of IL-11 in Wistar rats infected with Dengue virus serotype 3

\section{Effects of Monascus jmbA rice on increased platelets through changes in the levels of TNF- $\alpha$ in Dengue Virus Infection}

The mean increase in the levels of TNF$\alpha$ for the group treated with DVI and MJR was lower than that in the group treated with only DVI and a significant difference was found at $\mathrm{P}<0.05$ (Table 3); thus, this study demonstrated that administration of MJR had an effect on increased platelet count through changes in the levels of TNF$\alpha$ in Wistar rats infected with Dengue virus serotype 3 .

In addition to containing monacolin $\mathrm{K}$, MJR also contains dimerumic acid (an antioxidant), as well as metabolites ankavlafin and monascin which have an anti-inflammatory effect. ${ }^{6,17}$ The other study showed that the metabolites of Monascus purpureus rice, monacolin $\mathrm{K}$, ankaflavin and monascin, are capable of reducing adhesion molecules produced by cytokine TNF- $\alpha$ and reducing the intracellular formation of reactive oxygen species (ROS). ${ }^{5}$

Monacolin $\mathrm{K}$ or lovastatin are a class of statins or HMG Co-A Reductase inhibitors that, in addition to a cholesterol-lowering effect, have also anti-inflammatory effects. Statins may affect gene expression and function of cells of the natural and acquired immune systems, such as macrophages, dendritic cells, and T cells. Most of these effects are related to the blockade of statins in GTPaseisoprenylation. ${ }^{18}$

Statins can also cause a decrease in the expression of intercellular adhesion mole- cules in macrophages and macrophage and monocyte secretion of IL- 6 and TNF- $\alpha$. Activated macrophages will secrete IL-6 from fibroblasts through stimulation of TNF- $\alpha$ and subsequently IL- 6 will increase the production of thrombopoietin, which in turn will increase the platelet count. ${ }^{19}$

The present study showed the mechanism of the effects of MJR on increased platelets through the role of TNF- $\alpha$ and IL6 in Wistar rats infected with Dengue virus serotype 3 . The most dominant factor with regard to increased platelet count after administration of Monascus jmbA rice in infection of Dengue virus serotype 3 was TNF- $\alpha$.

\section{Therapeutic security}

The side effects of the use of MJR in laboratory rats investigated by the previous studies showed that those rats remain active and significant changes in conditions were not observed. ${ }^{4}$ Additionally, the present study also found data similar to those of the previous studies, as all groups of Wistar rats were active and that there were no cases of dropout.

\section{Conclusions}

In conclusion, Monascus jmbA rice was shown to increase platelet count through the role of TNF- $\alpha$ and IL- 6 in Wistar rats infected with Dengue virus serotype 3 . The most dominant factor with regard to increased platelet count after administration of Monascus jmbA rice in infection of DVI 3 was TNF- $\alpha$. Infection of Dengue virus serotype 3 could affect changes in platelets, IL-3, IL-6, IL-11, and TNF- $\alpha$ in Wistar rats but those changes were not statistically significant.

\section{References}

1. Aryati. Aspek laboratorium DBD. Dalam: S. Soegijanto, Edisi 2. Demam berdarah dengue. Surabaya: Airlangga University Press; 2006:117-132.

2. Chuansumrit A, Tangnararatchakit K. Pathophysiology and management of dengue hemorrhagic fever. Transfusion Altern Transfus Med 2006;8:3-11.

3. Funahara Y, Ogawa K, Fujita N, Okuno Y. Three possible triggers to induce thrombocytopenia in dengue virus infection. Southeast Asian J Trop Med Public Health 1987;18:351-5.

4. Tisnadjaja D. Memahami hubungan angkak dengan DBD. In: Penebar Swadaya eds. Bebas cholesterol dan Demam Berdarah dengan Angkak; 2006:56-62.

5. Muharni S, Almahdy A, Martini RD. Effect of the use of supplements Psidii folium extract (Psidium guajava linn.) and red fermented rice (Monascus purpureus) in increase of thrombocytes at dengue hemorrhagic fever (DHF) science in the installation of disease in hospital dr. M. Djamil Padang. 2011 Available from: http//pasca.unand.ac. id. Accessed: 5 March 2012.

6. Lin CP, Lin YL, Huang PH, et al. Inhibition of endothelial adhesion molecule expression by monascus purpureus-fermented rice metabolites, monakolin $\mathrm{K}$, ankaflavin, and monascin. J Sci Food Agric 2010;91:17518.

7. Miyajima A, Kitamura T, Harada N, et al. Cytokine receptors ang signal transduction. Annu Rev Immunol 1992;10: 295-331.

8. Kyle JL, Beathy R, Harris E. Dengue virus infects macrophages and denritic cells in a mouse model of infection. $\mathrm{J}$ Infect 2007;195:1808-87.

9. Peng T, Zhang J, An J. The animal models for dengue virus infection. Dengue Bulletin 2004;28:168-73.

10. Zompi S, Harris E. Animal Models of Dengue Virus Infection. Viruses 2012;4;6282.

11. Gibbons RV, Vaughn DW. Dengue: an escalating problem. BMJ 2002;324:1563-6.

12. Guglani L \& Kabra SK. T Cell immunopathogenesis of Dengue virus infection. Dengue Bull 2005;29:58-69.

13. Guilarde AO, Turchi MD, Siqueira JB, et al. Dengue and dengue hemorrhagic fever among adults: clinical outcomes related to viremia, serotypes, and antibody response. J Infect Dis 2008;197:817-823.

14. Hoff J. Methods of blood collection in the mouse. Lab Animal 2000;29:47-53.

15. Howard University. Intercardiac puncture for terminal blood collection in mive and rats. Howard University; 2003.

16. Parasuraman S, Ravendran R, Kesavan R. Blood sample collection in small labolatory animals. J Pharmacol 2010;1:87-93.

17. Arunachalam C, Narmadhapriya. Monascus fermented rice and its beneficial aspects: a new review. Asian J Pharm Clin Res 2011;4:29-31.

18. Bu D, Griffin G, Lichtman A. Mechanisms for the anti-inflammatory effects of statins. Curr Opin Lipidol 2011;22:165-70.

19. Kaushansky K. The molecular mechanism that control thrombopoiesis. J Clin Invest 2005;115:3339-47. 